\title{
Supramolecularly Regulated Ligands for Asymmetric Hydroformylations and Hydrogenations
}

\author{
Anton Vidal-Ferran, ${ }^{*[a, c]}$ Ignasi Mon, ${ }^{[a]}$ Antonio Bauzá, ${ }^{[b]}$ Antonio Frontera, ${ }^{[b]}$ and Laura Rovira ${ }^{[a]}$
}

\begin{abstract}
Herein we report the use of polyether binders as regulation agents (RAs) to enhance the enantioselectivity of rhodium-catalyzed

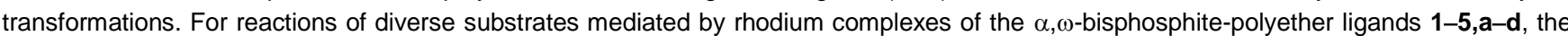
enantiomeric excess (ee) of hydroformylations was increased by up to $82 \%$ (substrate: vinyl benzoate, $96 \%$ ee), and the ee value of hydrogenations was increased by up to $5 \%$ (substrate: $N-(1-($ naphthalene-1-yl)vinyl)acetamide, $78 \%$ ee). The ligand design enabled the regulation of enantioselectivity by generation of an array of catalysts that simultaneously preserve the advantages of a privileged structure in asymmetric catalysis and offer geometrically close catalytic sites. The highest enantioselectivities in the hydroformylation of vinyl acetate with ligand $\mathbf{4} \mathbf{b}$ were achieved by using the $\mathrm{Rb}\left[\mathrm{B}\left(3,5-\left(\mathrm{CF}_{3}\right)_{2} \mathrm{C}_{6} \mathrm{H}_{3}\right)_{4}(\mathrm{RbBArF})\right.$ as the $\mathrm{RA}$. The enantioselective hydrogenation of the substrates $\mathbf{1 0}$ required the rhodium catalysts derived from bisphosphites $\mathbf{3 a}$ or $\mathbf{4 a}$, either alone or in combination with different RAs (sodium, cesium or $(R, R)$-bis(1-phenylethyl)ammonium salts). This design approach was supported by results from computational studies.
\end{abstract}

\section{Introduction}

Asymmetric catalysis enables unique and selective pathways for the conversion of simple compounds into enantiomerically pure complex molecules, often with significant advantages over non-catalytic methods. It has evolved greatly since the early 1970 s to now encompass nearly any transformation subject to three-dimensional bias. ${ }^{[1]}$ A general enantioselective catalyst for a given transformation does not exist. Structural changes to the substrate(s) and/or reagent(s) often translate to a loss of enantioselectivity. Several strategies have been devised to overcome this limitation. Ligand tuning ${ }^{[2,3]}$ in catalysis has allowed the rapid development of efficient catalytic systems for a broad substrate scope in a given transformation. Parallel chemistry and subsequent assessment of catalysts by automated high-throughput screening techniques have also allowed rapid identification of high-performing catalysts for a broad substrate scope. ${ }^{[4]}$ Supramolecular interactions have been used to construct the skeletons of the enantioselective catalysts with unprecedented ease ${ }^{[5]}$ or even to introduce stereogenicity into the catalyst. ${ }^{[6]}$

Within this context, regulation of a catalyst refers to modification of its active site upon binding of an effector molecule at a distinct site (known as the regulation site). Progress has been made in regulating the size and shape of a chiral catalyst by using a regulation agent (RA). ${ }^{[7]}$ This agent has also been used to change the first-sphere coordination geometry of the active metal in asymmetric catalysis. ${ }^{[8]}$ However, there are only scarce examples of fine modification of the active-site geometry that do not imply major alteration of the principal structural features of the asymmetric catalyst. ${ }^{[9,10]}$

In a previous study, ${ }^{[10]}$ we demonstrated that conformationally transformable $\alpha, \omega$-bisphosphite $\mathbf{3 b}$ (Scheme 1 ) behaved as a supramolecularly regulated ligand in asymmetric hydroformylations with moderate efficiency. To develop more efficient catalysts and gain a better understanding of the regulation mechanism, we describe a new set of enantiomerically pure supramolecular catalysts that incorporate a wider range of regulation centers (the (poly)ether chains 1, 2, 4, and 5; Scheme 1), new catalytic sites (those derived from the phosphite groups $\mathbf{c}$ and $\mathbf{d}$; Scheme 1) and new RAs (alkali metal and ammonium salts). A highly efficient supramolecular catalyst for asymmetric hydroformylations was identified. Furthermore, computational studies were performed; the results of which have elucidated the regulation mechanism. Lastly, the catalytic activity of rhodium pre-catalysts of the aforementioned supramolecular ligands was also assessed in asymmetric hydrogenations.

\section{Results and Discussion}

\section{Design and synthesis of supramolecularly regulated bisphosphite ligands and RAs}

With the aim of developing highly efficient catalysts for asymmetric hydroformylations and hydrogenations and gaining insight into the regulation mechanism, we have designed and prepared an array of highly diverse bisphosphite ligands by combining a linker group and a polyether chain for regulation (see the fragments in orange and blue, respectively, in Scheme 1) with stereogenic phosphite groups for catalysis (see the fragments in green in Scheme 1). The resulting ligands exhibit several characteristics: 


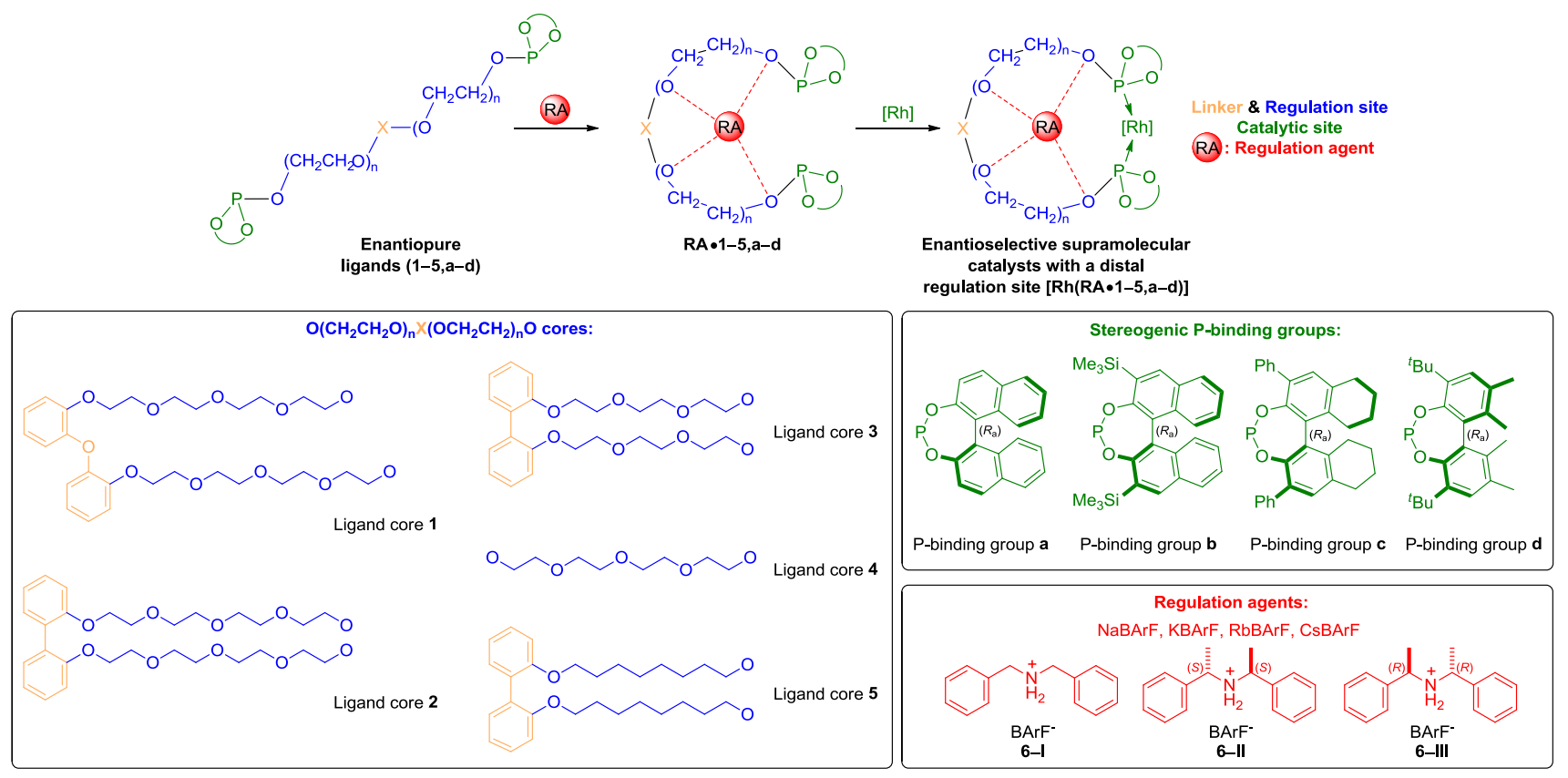

Scheme 1. Supramolecularly regulated bisphosphite ligands with a distal regulation site.

1) The proposed regulation sites encompass polyether groups of varying size, oxygen atom number, and spacer length (see the $\mathrm{O}\left(\mathrm{CH}_{2} \mathrm{CH}_{2} \mathrm{O}\right)_{n} \mathrm{X}\left(\mathrm{OCH}_{2} \mathrm{CH}_{2}\right)_{n} \mathrm{O}$ cores in Scheme 1), to offer a wide range of binding capacities to RAs of different size and types. ${ }^{[11,12]}$

2) The binding groups comprised a structurally diverse array of conformationally stable [1,1'-biaryl]-2,2'-diol-derived phosphites (see structures a-d in Scheme 1).

3) With regard to the RA, we considered that any polyether binder might prove utile. However, from the myriad possibilities available, ${ }^{[11]}$ we focused on alkali metal and ammonium salts (see Scheme 1). With the aim of facilitating higher binding strength between the proposed RAs and the polyether moiety, we considered salts with an adequate solubility profile in organic solvents and with a weakly coordinating anion. Thus, the $\left[\mathrm{B}\left(3,5-\left(\mathrm{CF}_{3}\right)_{2} \mathrm{C}_{6} \mathrm{H}_{3}\right)_{4}\right]^{-}$anion (hereafter, BArF) was deemed an attractive option, although other anions also were assessed.

The preparation of bisphosphite ligands is well documented, and relies on an O-phosphorylation of the diol of interest. ${ }^{[13 b]}$ Thus, compounds 1-5,a-d were synthesized this way (48 to $92 \%$ yield) from the corresponding diols and chlorophosphites in the presence of $\mathrm{NEt}_{3}$ as base. The synthetic protocols for bisphosphite-polyether ligands $\mathbf{1 - 5 , a - d}$, together with the preparation methods for the required starting materials, metal BArF salts, and compounds 6-I, 6-II and 6-III, are detailed in the Supporting Information.

\section{Studies on binding of the ligands $1-5, a-d$ to the RAs}

The design principle of the regulation mechanism proposed herein is the binding of suitable RAs to the regulation site (a polyether group). Metal cations bind to polyether groups through ion-dipole interactions, as do ammonium salts through hydrogen bonding. ${ }^{[11]}$ It is generally accepted that when the ionic radius of

the positively charged species matches the length and shape of the polyether chain, the binding will be strong. ${ }^{[11]}$

To begin studying supramolecular ligands with a distal regulation site, we examined the binding of various RAs (alkali metal and ammonium salts; Table 1 and 2) to bisphosphites $\mathbf{3 a}, \mathbf{3 b}, \mathbf{4 a}$ and $\mathbf{4 b}$ (see Figure 1 ). These compounds were chosen as a structurally representative set of the ligands $\mathbf{1 - 5 , a - d}$ on the basis of two considerations. Firstly, biphosphites $\mathbf{3 a}$ and $\mathbf{3} \mathbf{b}$ have a large binding site, whereas $\mathbf{4 a}$ and $\mathbf{4 b}$ have a small one, and secondly, biphosphites $\mathbf{3 b}$ and $\mathbf{4 b}$ have a substituent at the 3 and 3 ' positions in the binaphthyl moieties, whereas 3a and $\mathbf{4 a}$ do not. NaBArF and CsBArF were chosen as representative examples of salts with cationic species that have a small and large ionic radius, respectively $\left(\mathrm{Na}^{+}[0.98 \AA]\right.$ and $\left.\mathrm{Cs}^{+}[1.67 \AA]\right){ }^{[14]}$

The binding of the bisphosphites $\mathbf{3} \mathbf{a}, \mathbf{3} \mathbf{b}, \mathbf{4} \mathbf{a}$ or $\mathbf{4} \mathbf{b}$ to NaBArF or CsBArF was studied by using several spectroscopic techniques. Addition of increasing amounts of the RA to a solution of the bisphosphite (dichloromethane or toluene, plus a minimal amount of THF to ensure solubility of the RA throughout the titration) led to changes in the UV, ${ }^{1} \mathrm{H}$ or ${ }^{31} \mathrm{P}$ NMR spectra. ${ }^{[15]}$

Association constants between the bisphosphites and RAs were determined by multivariate factor analysis of titration data, considering a 1:1 binding model (see Table 1). ${ }^{[16]}$ Higher binding constants were found for the ligands without substituents in the 3 and 3' positions of the bisphosphite groups (ligands $3 \mathbf{a}$ and $\mathbf{4 a} ; \mathrm{K}>10^{6} \mathrm{M}^{-1}$; entries 1 and 3 in Table 1) compared with those of the 3,3'-disubstituted ones (ligands $\mathbf{3 b}$ and $\mathbf{4 b}$; $K$ value ca. $10^{4} \mathrm{M}^{-1}$; entries 2 and 4 in Table 1 ). NaBArF showed its greatest binding 
affinity with the 3,3'-unsubstituted ligand with the shorter polyether chain (ligand $\mathbf{4 a}$, entry 3 , third column in Table 1), whereas CsBArF achieved its greatest binding affinity with the analogous ligand with the longer polyether chain (ligand $3 a$, entry 1 , fourth column in Table 1).

The stoichiometry of the resulting complexes was determined by the method of continuous variations ${ }^{[17]}$ (for details, see the Supporting Information). All the studied ligands were capable of adapting to a 1:1 stoichiometry, independently of the size of the host cavity or the cation. This adaptability might be attributed to the high flexibility of the ligands $\mathbf{3 a}, \mathbf{3} \mathbf{b}, \mathbf{4 a}$ and $\mathbf{4 b}$.

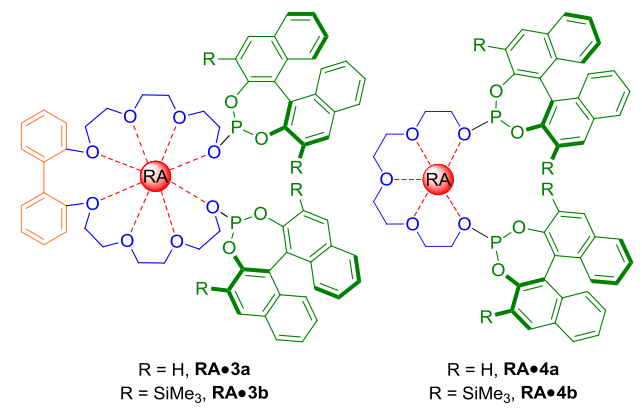

Figure 1. General structures for the complexes between a regulation agent (RA) and a bisphosphite (3a, 3b, $\mathbf{4 a}$ or $\mathbf{4 b})$.

Table 1. Binding constant data ${ }^{[a]}$ for complexation between ligands $\mathbf{3 a}, \mathbf{3 b}, \mathbf{4 a}$ or $\mathbf{4 b}$ and NaBArF or CsBArF.

\begin{tabular}{cccc}
\hline & \multicolumn{3}{c}{$K$-value $\left(\mathrm{M}^{-1}\right)$} \\
Entry & Ligand & NaBArF & CsBArF \\
\hline 1 & $\mathbf{3 a}^{[\mathrm{b}]}$ & $4.5 \times 10^{6}\left( \pm 3 \times 10^{5}\right)$ & $1.2 \times 10^{8}\left( \pm 7 \times 10^{7}\right)$ \\
2 & $\mathbf{3 b}^{[\mathrm{c}]}$ & $1.5 \times 10^{4}\left( \pm 1 \times 10^{3}\right)$ & $5.2 \times 10^{3}\left( \pm 3 \times 10^{2}\right)^{[\mathrm{d}]}$ \\
3 & $\mathbf{4 a}^{[\mathrm{b}]}$ & $3.0 \times 10^{7}\left( \pm 4 \times 10^{6}\right)$ & $8.7 \times 10^{6}\left( \pm 2 \times 10^{6}\right)$ \\
4 & $\mathbf{4 b}^{[\mathrm{c}]}$ & $5.6 \times 10^{3}\left( \pm 4 \times 10^{2}\right)$ & $1.4 \times 10^{4}\left( \pm 6 \times 10^{2}\right)$ \\
\hline
\end{tabular}

[a] Average value at $298 \mathrm{~K}$ of at least two independent measurements. The mean absolute error $\left(M A E=1 / \mathrm{n} \Sigma_{i} \mathrm{IK}_{i}-\mathrm{KI}\right)$ is in parentheses. [b] Measured by UV/Vis spectrophotometry $\left(\mathrm{CH}_{2} \mathrm{Cl}_{2} / \mathrm{THF}, 99.8: 0.2 \mathrm{v} / \mathrm{v}\right)$.[c] Measured by NMR spectroscopy $\left(\left[\mathrm{D}_{8}\right]\right.$ toluene/[$\left.\left[\mathrm{D}_{8}\right] \mathrm{THF}, 95: 5 \mathrm{v} / \mathrm{v}\right)$. [d] This $K$ value was already reported $^{[10]}$ but has been included here for comparison.

The binding constants of the enantiomerically pure ammonium salts $\mathbf{6 - I I}$ and $\mathbf{6 - I I I}$ to the bisphosphite ligands $\mathbf{3 a}$, $\mathbf{4 a}$ or $\mathbf{4 b}$ were determined at $298 \mathrm{~K}$ by using isothermal titration calorimetry (ITC). ${ }^{[18]}$ The binding constants, together with $\Delta H$ and $\Delta S$ (also determined by ITC), are summarised in Table 2. In all cases, the binding constants were approximately $10^{4} \mathrm{M}^{-1}$. Analysis of the ITC data also revealed a 1:1 ratio between each ligand (3a, $\mathbf{4 a}$ or $\mathbf{4 b}$ ) and each ammonium salt (6-II or $\mathbf{6}-\mathbf{I I I})$. Furthermore, all the complexation processes were exothermal

\begin{tabular}{|c|c|c|c|c|c|}
\hline \multirow[t]{2}{*}{ Entry } & \multirow[t]{2}{*}{ Ligand } & \multicolumn{2}{|c|}{$K$-values ${ }^{[\mathrm{b}]}$ with 6 -II } & \multicolumn{2}{|c|}{$K$-values ${ }^{[b]}$ with 6 -III } \\
\hline & & $\Delta H^{[\mathrm{c}]}$ & $T \Delta S^{[\mathrm{c}]}$ & $\Delta H^{[c]}$ & $T \Delta S^{[c]}$ \\
\hline \multirow[t]{2}{*}{1} & $3 a$ & \multicolumn{2}{|c|}{$1.2 \times 10^{4}\left( \pm 2 \times 10^{2}\right)$} & \multicolumn{2}{|c|}{$1.7 \times 10^{4}\left( \pm 8 \times 10^{2}\right)$} \\
\hline & & -7.9 & -2.4 & -7.0 & -1.4 \\
\hline \multirow[t]{2}{*}{2} & $4 a$ & \multicolumn{2}{|c|}{$9.4 \times 10^{3}\left( \pm 1 \times 10^{3}\right)$} & \multicolumn{2}{|c|}{$1.3 \times 10^{4}\left( \pm 8 \times 10^{2}\right)$} \\
\hline & & -7.3 & -2.0 & -7.2 & -1.7 \\
\hline \multirow[t]{2}{*}{3} & $4 b$ & \multicolumn{2}{|c|}{$7.3 \times 10^{3}\left( \pm 2 \times 10^{2}\right)$} & \multicolumn{2}{|c|}{$8.6 \times 10^{3}\left( \pm 6 \times 10^{2}\right)$} \\
\hline & & -7.8 & -2.7 & -8.2 & -2.9 \\
\hline
\end{tabular}

[a] Measured in $\mathrm{CH}_{2} \mathrm{Cl}_{2}$ at $298 \mathrm{~K}$. [b] (in $\mathrm{M}^{-1}$ ); see note [a] in Table 1. [c] $\mathrm{kcal} \cdot \mathrm{mol}^{-1}$. 
$(\Delta H<0)$ but entropically unfavorable $(\Delta S<0)$, as would be expected when a conformationally transformable host (ligand 3 a, 4 a or 4b) loses conformational freedom upon complexation.

\section{Complexation studies of ligands $1-5, a-d$ towards pre-catalysts for hydroformylations and hydrogenations}

To elucidate the structure of catalytically relevant species, complexation experiments (in the presence and absence of an RA) were performed between representative bisphosphites and standard catalyst precursors $\left(\left[\mathrm{Rh}\left(\mathrm{\kappa}^{2} \mathrm{O}, \mathrm{O}^{\prime}-\mathrm{acac}\right)(\mathrm{CO})_{2}\right](\mathrm{acac}=\mathrm{acetylacetonate})\right.$ for hydroformylation and $\left[\mathrm{Rh}(\mathrm{cod})_{2}\right][\mathrm{BArF}]$ (cod=1,5-cyclooctadiene) for hydrogenation).

$\left[\mathrm{Rh}\left(\kappa^{2} \mathrm{O}, \mathrm{O}^{\prime}-\mathrm{acac}\right)(\mathrm{CO})_{2}\right]$ and $\mathbf{4 b}$ were reacted at $40{ }^{\circ} \mathrm{C}$ in a typical solvent mixture for hydroformylations under 10 bar of $1: 1$ $\mathrm{CO} / \mathrm{H}_{2}$. Interestingly, the addition of equimolar amounts of $\left[\mathrm{Rh}\left(\kappa^{2} \mathrm{O}, \mathrm{O}^{\prime}-\mathrm{acac}\right)(\mathrm{CO})_{2}\right]$ to a solution of $\mathbf{4 b}$, followed by reaction for $2 \mathrm{~h}$, did not lead to the expected hydrido-dicarbonyl chelate $\left[R h(H)(C O)_{2}\left(\kappa^{2} P, P^{\prime}-4 b\right)\right]$, but rather to the complex $\left[\mathrm{Rh}\left(\kappa^{2} \mathrm{O}, \mathrm{O}^{\prime}-\mathrm{acac}\right)(\mathrm{CO})\left(\kappa^{1} \mathrm{P}-\mathbf{4 b}\right)\right]$ (see Scheme 2), which was formed upon displacement of a CO ligand by a phosphite group. The complex $\left[\mathrm{Rh}\left(\kappa^{2} \mathrm{O}, \mathrm{O}^{\prime}-\mathrm{acac}\right)(\mathrm{CO})\left(\kappa^{1} \mathrm{P}-\mathbf{4 b}\right)\right]$ evolved to the expected chelate $\left[\mathrm{Rh}(\mathrm{H})(\mathrm{CO})_{2}\left(\kappa^{2} \mathrm{P}, \mathrm{P}^{\prime}-\mathbf{4 b}\right)\right]$ with time $(16 \mathrm{~h}$ total), even in the absence of a polyether chain binder.

Binding between RbBArF and the ligand $\mathbf{4 b}$ is strong $\left(\left(1 \times 10^{4} \pm 2 \times 10^{3}\right) \mathrm{M}^{-1}\right.$; measured by NMR spectroscopy at $298 \mathrm{~K}$ in $\left[\mathrm{D}_{8}\right]$ toluene/[ $\left.\mathrm{D}_{8}\right]$ THF $(99.8: 0.2 \mathrm{v} / \mathrm{v})$; data not shown in Table 1). This high affinity translates into the efficient formation under hydroformylation reaction conditions of the chelate $\left(\left[\mathrm{Rh}(\mathrm{H})(\mathrm{CO})_{2}\left(\kappa^{2} \mathrm{P}, \mathrm{P}^{\prime}-\mathrm{RbBArF} \cdot 4 \mathrm{~b}\right)\right]\right.$ ) after only $2 \mathrm{~h}$ (instead of the $16 \mathrm{~h}$ required for the reaction without RA; see Scheme 2). This behavior clearly demonstrated that binding of the RA to $\mathbf{4 b}$, serves to bring the two terminal phosphorus groups closer together, thereby favoring the formation of chelate species.

Formation of the rhodium chelates $\left[R h(H)(C O)_{2}\left(\kappa^{2} P, P^{\prime}-4 b\right)\right]$ and $\left[R h(H)(C O)_{2}\left(\kappa^{2} P, P^{\prime}-R b B A r F \cdot 4 b\right)\right]$ was proven by using standard spectroscopic techniques. ${ }^{[15]}$ NMR spectroscopy analysis indicated that the hydrido ligand has a preference for a cis orientation relative to the P-ligating groups, which are coordinated in an equatorial-equatorial fashion to a trigonal-bipyramidal rhodium center. ${ }^{[19]}$ Other rhodium complexes with this type of spatial orientation between the bisphosphite ligand and the hydride have been reported as active hydroformylation catalysts. ${ }^{[19 b]}$

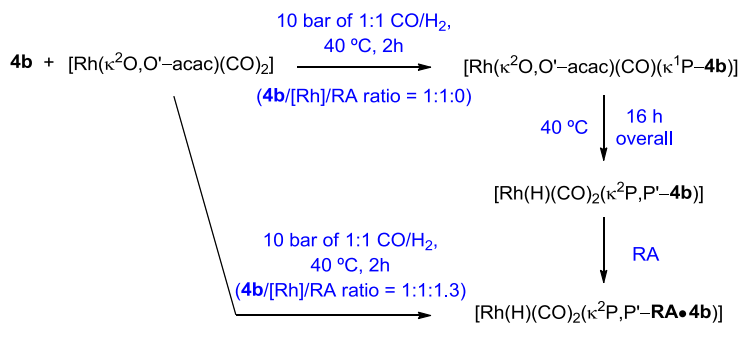

Experiments in $\left[\mathrm{D}_{8}\right]$ toluene/[ $\left.\mathrm{D}_{8}\right] \mathrm{THF}(97: 3 \mathrm{v} / \mathrm{v})$; RA $=\mathrm{RbBArF}$

Scheme 2. Complexation of $\left[\mathrm{Rh}\left(\mathrm{\kappa}^{2} \mathrm{O}, \mathrm{O}^{\prime}-\mathrm{acac}\right)(\mathrm{CO})_{2}\right]$ and $\mathbf{4 b}$ in the presence or absence of RbBArF.

Complexation studies similar to those described above were performed for asymmetric hydrogenation, by using [Rh( $\left.\operatorname{cod})_{2}\right][\mathrm{BArF}]$, the ligand $\mathbf{3 a}$ and the regulating agent NaBArF. Formation of the chelate $\left[\mathrm{Rh}(\operatorname{cod})\left(\kappa^{2} \mathrm{P}, \mathrm{P}^{\prime}-3 \mathbf{a}\right)\right][\mathrm{BArF}]$ was unequivocally proven by using standard spectroscopic techniques after treating stoichiometric amounts of $3 \mathbf{a}$ with the rhodium precursor. ${ }^{[15]}$ When an analogous complexation experiment was performed by using a preformed complex of NaBArF and 3a (ratio $[\mathrm{Rh}] / 3 \mathbf{a} / \mathrm{NaBArF}=1: 1: 1.3)$, an analogous chelate was obtained $\left[\mathrm{Rh}(\operatorname{cod})\left(\kappa^{2} \mathrm{P}, \mathrm{P}^{\prime}-\mathrm{NaBArF} \cdot 3 \mathbf{a}\right)\right][\mathrm{BArF}]$, according to the spectral data obtained. ${ }^{[15]}$ Thus, we concluded that suitable rhodium chelates for asymmetric hydrogenation had been efficiently and selectively formed.

\section{Asymmetric hydroformylation of alkenes catalyzed by rhodium complexes of bisphosphite ligands 1-5,a-d}

With the supramolecular ligands and binding parameters of representative bisphosphite ligands (3a, $\mathbf{3 b}$, $\mathbf{4 a}$ and $\mathbf{4 b})$ in hand, we then turned our attention to applications in asymmetric catalysis. The ligands were tested in asymmetric hydroformylation (AHF), in which olefins are converted into enantiomerically enriched aldehydes in a single step. ${ }^{[20]}$ The only bisphosphite ligands that we had explored in the previously published studies were $\mathbf{3} \mathbf{a}$ and $\mathbf{3} \mathbf{b}$, whose polyether chains contain eight oxygens. ${ }^{[10]}$ With the aim of developing more efficient supramolecularly regulated ligands, we sought to assess bisphosphites containing a longer polyether chain (ligands $\mathbf{1 a}$ and $\mathbf{2 a}$ ) or a shorter one (ligand $\mathbf{4 a}$ ) in AHF of vinyl acetate $\mathbf{7 a}$, a commonly used benchmark substrate in this chemistry. The reaction conditions and results are summarised in Scheme 3 and Table 3, respectively.

$$
\begin{aligned}
& \text { 7a } \frac{\begin{array}{c}
\text { Bisphosphite ligand } \\
(\mathrm{RA} / \mathrm{L} \text { igand/[Rh] ratio }=0.78: 0.6: 0.5)
\end{array}}{\left[\mathrm{Rh}\left(\mathrm{\kappa}^{2} \mathrm{O}, \mathrm{O}^{\prime}-\mathrm{acac}\right)(\mathrm{CO})_{2}\right](\text { cat. })} \\
& 10 \text { bar of } 1: 1 \mathrm{CO} / \mathrm{H}_{2} \\
& \text { toluene/THF }(97: 3 \mathrm{v} / \mathrm{v})
\end{aligned}
$$

Scheme 3. Asymmetric hydroformylation of vinyl acetate mediated by regulable bisphosphite ligands. 


\begin{tabular}{|c|c|c|c|c|c|}
\hline Entry & Ligand & RA & $\begin{array}{l}\text { Conv. } \\
(\%)^{[b]}\end{array}$ & $\mathrm{b} / \mathrm{l}$ ratio ${ }^{[\mathrm{b}]}$ & $\begin{array}{c}e e(\%))^{[\mathrm{b}]} \\
\text { (config.) }^{[\mathrm{c}]}\end{array}$ \\
\hline 1 & $1 a$ & $\mathrm{NaBArF}$ & 38 & $96: 4$ & $26,(S)$ \\
\hline 2 & $2 a$ & $\mathrm{NaBArF}$ & 48 & $98: 2$ & $20,(S)$ \\
\hline 3 & $3 a$ & none & 99 & $90: 10$ & $17,(S)$ \\
\hline 4 & $3 a$ & $\mathrm{NaBArF}$ & 84 & $99: 1$ & $26,(S)$ \\
\hline 5 & $3 a$ & $\mathrm{NaBF}_{4}$ & 99 & $90: 10$ & $17,(S)$ \\
\hline 6 & $3 a$ & $\mathrm{NaClO}_{4}$ & 99 & $91: 9$ & $17,(S)$ \\
\hline 7 & $4 a$ & $\mathrm{NaBArF}$ & 66 & $97: 3$ & $10,(S)$ \\
\hline
\end{tabular}

[a] The AHF were performed in a parallel autoclave. The reaction conditions are the same as those shown in Scheme $3(\mathrm{~S} / \mathrm{C}$ ratio $=200: 1 ;[7 \mathrm{a}]=0.26 \mathrm{M} ; \mathrm{T}=70$ ${ }^{\circ} \mathrm{C} ; t=5 \mathrm{~h}$ ). [b] Conversion, and b/l ratio, were determined by GC analysis ( $\beta$-Dex 225). ee Values were determined by GC analysis on a chiral stationary phase ( $\beta$-Dex 225, for details, see the Supporting Information). [c] The configuration of the branched product was assigned by comparison with previously reported elution-order data (for details, see the Supporting Information).

The results in Table 3 reveal that the ligands with a longer polyether chain (1a and $\mathbf{2} \mathbf{a}$ ) than those of ligands $\mathbf{3 a}$ or $\mathbf{4 a}$ led to the lowest conversions (compare entries 1 and 2 with 4 or 7 in Table 3). Although correlating the enantioselectivity to the RA is not trivial, there was an observable trend linking the regioselectivity to the counterion used: with ligand $\mathbf{3 a}$, the BArF anion provided higher regioselectivities $(\mathrm{b} / \mathrm{l}$ ratio $=99: 1)$ than those of the $\mathrm{BF}_{4}$ or $\mathrm{ClO}_{4}$ analogues $(\mathrm{b} / \mathrm{l}$ ratio for each = ca., 90:10; compare entry 4 with entry 6 in Table 3). Thus, only BArF salts were considered in subsequent optimization studies.

We then endeavored to optimize the enantioselectivity of the AHF of vinyl acetate by tuning the reaction parameters and the catalyst structure. Firstly, the reactions were run at lower temperature $\left(40{ }^{\circ} \mathrm{C}\right.$ instead of $\left.70{ }^{\circ} \mathrm{C}\right)$, on the basis of the established premise that lowering the temperature in AHF offers higher enantioselectivity. ${ }^{[20]}$ Secondly, a representative set of alkali metal salts (NaBArF or CsBArF) was assessed as RAs. Lastly, a diverse set of additional bisphosphite ligands was explored: these combined the shortest polyether chains (either $\mathbf{3}$ or $\mathbf{4}$ in Scheme 1) with a phosphite moiety, either 3,3'-unsubstituted (fragment a) or 3,3'disubstituted (groups $\mathbf{b}-\mathbf{d}$ ). This set also included the bisphosphite ligand $\mathbf{5} \mathbf{b}$, which is the same size as $\mathbf{3} \mathbf{b}$, but lacks the four central oxygens in the polyether chain. We reasoned that, in terms of the regulation mechanism presented in this paper, use of the new ligand $\mathbf{5 b}$ would entail much weaker supramolecular interactions ${ }^{[21]}$ and therefore, that AHF reactions with $\mathbf{5 b}$ should be considered to be a background experiment for the aforementioned regulation mechanism. The reactions conditions and results are summarised in Table 4.

Table 4. Catalytic studies on the hydroformylation of $7 \mathbf{a}$ using Rh-complexes of ligands $\mathbf{3 a - d ,} \mathbf{4 a , b}$ or $\mathbf{5 b}$ and a set of RAs. ${ }^{[a]}$

\begin{tabular}{|c|c|c|c|c|}
\hline \multirow[b]{2}{*}{ Entry } & \multirow[b]{2}{*}{ Ligand } & \multicolumn{3}{|c|}{$\begin{array}{l}\text { Conv. } \\
(\%){ }^{[b]} \mathrm{b} / / \text { ratio }{ }^{[b]} \text { ee } \\
(\%)^{[b]}(\text { config. })^{[c]}\end{array}$} \\
\hline & & $\mathrm{RA}=$ none & $\mathrm{RA}=\mathrm{NaBArF}$ & $\mathrm{RA}=\mathrm{CsBArF}$ \\
\hline 1 & $3 a$ & $\begin{array}{l}\text { 69, 94:6, } \\
17(S)^{[d]}\end{array}$ & $\begin{array}{c}12,>99: 1 \\
21(S)\end{array}$ & $\begin{array}{c}46,90: 10 \\
29(S)\end{array}$ \\
\hline 2 & $3 b$ & $\begin{array}{l}76,99: 1 \\
28(S)^{[d]}\end{array}$ & $\begin{array}{c}57,>99: 1 \\
23(S)^{[d]}\end{array}$ & $\begin{array}{c}95,>99: 1 \\
90(S)^{[d]}\end{array}$ \\
\hline 3 & $3 c$ & $\begin{array}{c}55,98: 2 \\
65(S)\end{array}$ & $\begin{array}{c}79,>99: 1 \\
86(S)\end{array}$ & $\begin{array}{c}>99,>99: 1 \\
80(S)\end{array}$ \\
\hline 4 & $3 d$ & $\begin{array}{c}22,>99: 1 \\
16(S)\end{array}$ & $\begin{array}{c}13,>99: 1 \\
19(S)\end{array}$ & $\begin{array}{c}>99,>99: 1 \\
86(S)\end{array}$ \\
\hline 5 & $4 a$ & $\begin{array}{c}\text { 33, 93:7, } \\
15(S)\end{array}$ & $\begin{array}{c}61,97: 3 \\
12(S)\end{array}$ & $\begin{array}{c}9,>99: 1 \\
54(S)\end{array}$ \\
\hline 6 & $4 b$ & $\begin{array}{c}18,90: 10 \\
35(S)\end{array}$ & $\begin{array}{c}87,>99: 1 \\
74(S)\end{array}$ & $\begin{array}{c}>99,>99: 1 \\
96(S)\end{array}$ \\
\hline 7 & $5 b$ & $\begin{array}{c}44,94: 6 \\
22(S)\end{array}$ & $\begin{array}{c}12,>99: 1 \\
22(S)\end{array}$ & $\begin{array}{c}74,>99: 1 \\
21(S)\end{array}$ \\
\hline
\end{tabular}

[a] For the reaction conditions see note [a] in Table 3, with these exceptions: $\mathrm{T}=40{ }^{\circ} \mathrm{C}, t=5 \mathrm{~h}$. [b, c] See notes [b] and [c] in Table 3 . [d] These results have already been published ${ }^{[10]}$ but are included here for comparison. 
When no RA was used (see the third column from the left in Table 4), the AHF products were obtained in conversions from 18 to $76 \%$; b/l ratios from 90:10 to > 99:1; and ee values from 15 to $65 \%$ in favor of the product $(S)-8$ a. The use of NaBArF or CsBArF as RAs for ligands $\mathbf{1 - 5 , a - d ~ e n a b l e d ~ b e t t e r ~ c o n v e r s i o n s ~ i n ~ m o s t ~ c a s e s ~ a n d , ~ w i t h ~ f e w ~ e x c e p t i o n s , ~ h i g h e r ~ b / l ~ r a t i o s ~ a n d ~ g r e a t e r ~}$ enantiopurity of the product (see Table 4). Greater regulation effects in the ee values were achieved with the ligands containing a 3,3'-substituted-1,1'-[biaryl] moiety (the ligands $\mathbf{3 b}$-d, and $\mathbf{4 b}$; increase in the ee value of up to $61 \%$; $96 \%$ ee; see entry 6 in Table 4 ) relative to those achieved with the unsubstituted analogues (the ligands $3 \mathbf{3 a}$ and $\mathbf{4 a}$; ee increase of up to $39 \%$; $54 \%$ ee; see entry 5 in Table 4). The optimal phosphite group was structure $\mathbf{b}$, as evidenced by the fact that the ligand $\mathbf{3} \mathbf{b}$ (entry 2 , Table 4) gave a higher ee value than that of its analogues with the same polyether core and different phosphite groups (ligands $\mathbf{3 c}$ and $\mathbf{3 d}$; entries 3 and 4 , Table 4).

As previously mentioned, we reasoned that our proposed regulation mechanism through supramolecular interactions at the

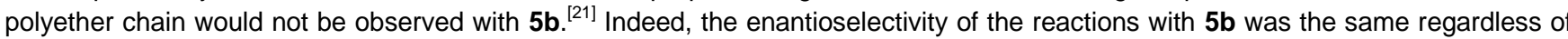
whether or not RAs were present (entry 7, Table 4). This finding corroborates the premise that interaction between the polyether chain of the ligand and the RA is crucial for improving the stereodifferentiating ability of the catalyst.

Further optimization studies were performed with the highest-performing ligand $\mathbf{4 b}$ (entry 6 , Table 4). Of all the RA/ligand combinations tested for AHF of vinyl acetate, RbBArF•4b gave the best results: Full conversion, complete regioselectivity and $99 \%$ ee towards the branched product (see entry 4, in Table 5). For all the assays summarized in Table 5, a substrate-to-catalyst (S/C) ratio of $100: 1$ was used. However, the amount of rhodium catalyst of RbBArF•4b was reduced to 0.1 mol\% ${ }^{[22]}(\mathrm{S} / \mathrm{C}=1000: 1)$, with almost no consequent decrease in catalytic activity (99\% conv., b/l ratio : > 99:1 and 97\% ee for (S)-8a; data not shown in Table 5). Interestingly, these results obtained with RbBArF•4b rival those achieved with the highest performing Rh-mediated AHF catalyst reported for vinyl acetate. ${ }^{[23]}$ Furthermore, RbBArF•4b proved to be a much

Table 5. Catalytic studies on the hydroformylation of $7 \mathbf{a}$ using $\mathrm{Rh}$ complexes of the ligand $\mathbf{4 b}$ and a set of RAs ${ }^{[a]}$

\begin{tabular}{|c|c|c|}
\hline Entry & RA & 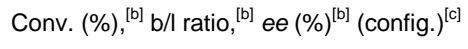 \\
\hline 1 & none & $18,90: 10,35(S)$ \\
\hline 2 & NaBArF & $87,>99: 1,74(S)$ \\
\hline 3 & KBArF & $>99,>99: 1,98(S)$ \\
\hline 4 & RbBArF & $>99,>99: 1,99(S)$ \\
\hline 5 & CsBArF & $>99,>99: 1,96(S)$ \\
\hline 6 & $6-11$ & $50,>99: 1,40(S)$ \\
\hline 7 & 6-III & $46,>99: 1,40(S)$ \\
\hline
\end{tabular}

[a]- [c] See notes [a], [b] and [c] in Table 3 and Table 4.

more efficient ligand in terms of activity, regioselectivity, and enantioselectivity relative to known ligands containing the same phosphite group but lacking a regulation site. ${ }^{[24]}$

Interestingly, the use of KBArF or CsBArF rather than RbBArF also provided very high enantioselectivities (98 and $96 \%$ ee, respectively; see entries 3 and 5 in Table 5). In contrast, when the enantiomerically pure derivatives 6-II and 6-III were used as RAs, the activity of the catalysts derived from $\mathbf{4} \mathbf{b}$ was worse (entries 6 and 7 in Table 5 ).

Conversion curves for hydroformylation of $\mathbf{7 a}$ (vinyl acetate), as catalyzed by rhodium complexes of RbBArF•4b, were recorded from the gas-uptake profiles ${ }^{[15]}$ (see Figure 2), and then used to calculate TOF values at approximately $50 \%$ conversion $\left(\mathrm{TOF}_{1 / 2}\right.$ ). Interestingly, the AHF of 7a without catalyst incubation, and without using a RA, under 10 bar of syngas $\left(\mathrm{CO} / \mathrm{H}_{2} 1: 1\right)$ at $40 \stackrel{\circ}{\circ} \mathrm{C}$, took about 6 hours to start (see black curve in Figure 2). This observation corroborates the complexation results discussed in the previous section (i.e., the hydroformylation-active hydrido-dicarbonyl complexes of $\mathbf{4 b}$ are not formed immediately). However, when the same reaction was performed under incubation conditions (by stirring $\left[\mathrm{Rh}\left(\kappa^{2} \mathrm{O}, \mathrm{O}^{\prime}-\mathrm{acac}\right)(\mathrm{CO})_{2}\right]$ and $\mathbf{4 b}$ for $16 \mathrm{~h}$ under syngas at $40 \stackrel{\circ}{\circ}$ ), the hydroformylation began as soon as the vinyl acetate was added to the reaction mixture (see blue curve in Figure 2). ${ }^{[2]}$ Interestingly, when the rhodium complexes of RbBArF• $\mathbf{4 b}$ were used, consumption of syngas was detected from the beginning of the experiment: a clear indication that the catalytically active complexes had quickly formed. In addition to an increase in the ee value (entry 4 in Table 5), the RA provokes a reduction in the catalyst-activation time (compare the red and black curves in Figure 2), brought about by the binding of the RA (i.e., RbBArF helping to fold ligand $\mathbf{4 b}$ into the conformation required for bidentate coordination to the rhodium center). Furthermore, the RA enhances turnover frequency: TOF $_{1 / 2}=177 \mathrm{~h}^{-1}$ or $40 \mathrm{~h}^{-1}$ in the presence or absence of RbBArF, respectively. 


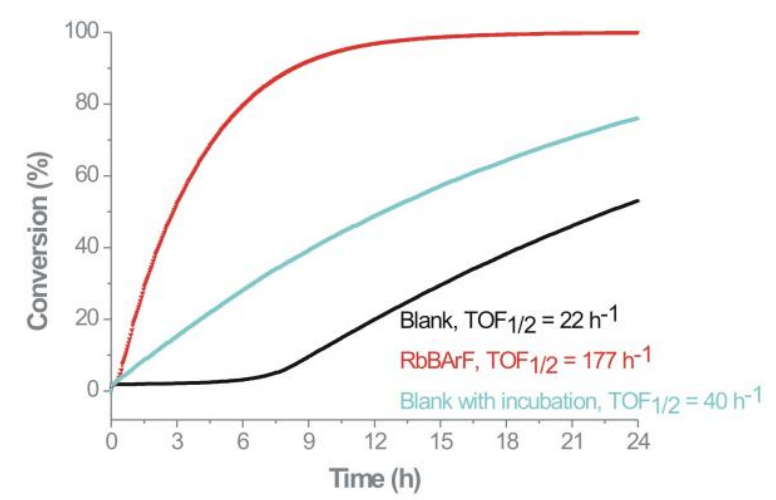

Figure 2. Conversion plotted against reaction time for the AHF of $7 a$ mediated by $\operatorname{RbBArF} \cdot 4 b(S / C=1000: 1)$.

We then studied the catalytic activity of the highest performing catalyst (rhodium complexes of RbBArF•4b) in the AHF of diverse alkenes, comprising vinyl esters 7a-c, styrene 7d and the allylic alcohol 7e (see Scheme 4 and Table 6).

When the AHF of the vinyl esters was catalyzed by a rhodium complex of ligand $\mathbf{4 b}$ without RA, the enantioselectivity was poor; however, when the RA/ligand combination RbBArF•4b was used, the enantioselectivity, conversion and regioselectivity of the process were much higher. For example, with $\operatorname{RbBArF} \cdot 4 b$

the enantioselectivity for $8 \mathrm{c}$ was $82 \%$ higher than that achieved

in the reaction in which no RA was used (96\% ee compared with $14 \%$ ee without the RA; see entry 3 in Table 6). Furthermore, to the best of our knowledge, the ee values achieved for $\mathbf{8 b}\left(99 \%\right.$ ee) and $\mathbf{8 c}\left(96 \%\right.$ ee) are the best values ever reported. ${ }^{[26]}$ Unfortunately, the use of the RA led to lower regioselectivity and enantioselectivity for styrene (7d; see entry 4 in Table 6). In contrast, with $\mathrm{RbBArF} \cdot 4 \mathrm{~b}$ the enantioselectivity for the allylic alcohol $7 \mathrm{e}$ was $18 \%$ higher than without the RA ( $25 \%$ ee compared with $7 \%$ ee; see entry 5 in Table 6, although the use of RbBArF did imply worse regioselectivity (entry 5 in Table 6).

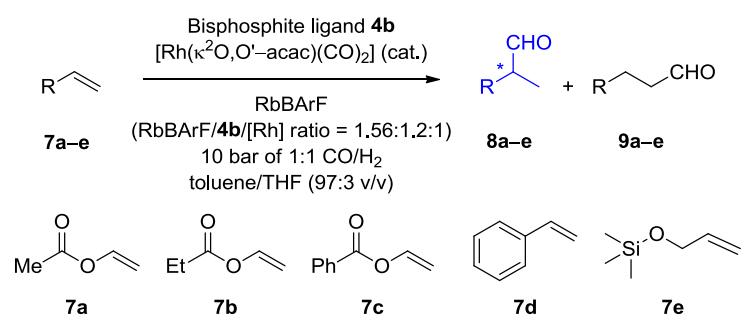

Scheme 4. Asymmetric hydroformylation of the alkenes 7a-e.

Table 6. Studies on $\mathrm{AHF}^{[\mathrm{a}]}$ of $\mathbf{7 a - e}$ using rhodium complexes of the ligand $\mathbf{4 b}$ with or without $\mathrm{RA}(\mathrm{RbBArF})$

Conv. $(\%),{ }^{[b]} \mathrm{b} / \mathrm{l}$ ratio, ${ }^{[\mathrm{b}]} e e(\%)^{[\mathrm{b}]}(\text { config. })^{[\mathrm{c}]}$

\begin{tabular}{|c|c|c|c|}
\hline Entry & Alkene & $\mathrm{RA}=$ none & $\mathrm{RA}=\mathrm{RbBArF}$ \\
\hline $1^{[\mathrm{d}]}$ & $7 a$ & $18,90: 10,35(S)$ & $>99,>99: 1,99(S)$ \\
\hline 2 & $7 b$ & $93,96: 4,36(S)$ & $>99,>99: 1,99(S)$ \\
\hline 3 & 7c & $97,98: 2,14(S)$ & $99,>99: 1,96(S)$ \\
\hline 4 & $7 d$ & $>99,95: 5,12(S)$ & $57,80: 20,5(S)$ \\
\hline 5 & $7 e$ & $>99,{ }^{[\mathrm{e}]} 59: 41,{ }^{[\mathrm{e}]} 7(S)$ & $>99,{ }^{[\mathrm{e}]} 18: 82,{ }^{[\mathrm{e}]} 25(S)$ \\
\hline
\end{tabular}

$[a, b, c]$ See notes [a], [b], and [c] in Table 3 and Table 4. [d] Although these results appear in Table 4, they have been included for comparison. [e] Conv. and b/l product ratio were determined by using ${ }^{1} \mathrm{H}$ NMR spectroscopy.

\section{Computational studies on the geometry of the complexes $\left[\mathrm{Rh}(\mathrm{H})(\mathrm{CO})_{2}(\mathrm{RA} \cdot 4 \mathrm{~b})\right]$}

To gain insight into the structural and geometric contributions of each component in the hydrido-dicarbonyl $\mathrm{Rh}^{\prime}$ complexes of the highest-performing ligand $\mathbf{4 b}$, either with or without RA, computational studies at the DFT level of theory ${ }^{[27]}$ were performed. Because these complexes have proven to be the catalyst resting-states in hydroformylations, ${ }^{[28]}$ we reasoned that studying their geometries 
would provide insight into the regulation mechanism. We focused on three geometrical parameters that could have a priori the greatest potential impact on catalytic performance: $\mathrm{P}-\mathrm{Rh}-\mathrm{P}$ bond angle $(\beta)$, dihedral angle $(\theta)$ in the binaphthyl groups, and phosphorus-rhodium distance $\left(d_{\mathrm{P}-\mathrm{Rh}}\right)$ (see Figure 3$)$. The calculated values for these parameters are listed in Table 7.

For the $\mathrm{P}-\mathrm{Rh}-\mathrm{P}$ bond angle $(\beta)$ of the rhodium complexes of $\mathbf{4 b}$, the general trend observed is that the size of the ionic radius in the RA cation (no RA to $2.7 \AA$ ) directly correlates to the width of the bond angle (from 113 to $121^{\circ}$ ).

As for the $\mathrm{P}-\mathrm{Rh}$ distance $\left(d_{\mathrm{P}-\mathrm{Rh}}\right)$ in these complexes, the values calculated for the complex without RA was the same as that for the complexes with the two largest cations in the RAs

Table 7. Calculated geometrical parameter values for $\left[\mathrm{Rh}(\mathrm{H})(\mathrm{CO})_{2}(\right.$ alkali metal•4b) $]$ and $\left[\mathrm{Rh}(\mathrm{H})(\mathrm{CO})_{2}(\mathbf{4 b})\right]$

\begin{tabular}{|c|c|c|c|c|c|}
\hline Entry & \multicolumn{2}{|c|}{ Cation and ionic radius $(\AA)^{[a]}$} & $\mathrm{P}-\mathrm{Rh}-\mathrm{P}$ angle $(\beta)^{[\mathrm{b}]}$ & Dihedral angle $(\theta)^{[\mathrm{c}]}$ & $d_{\mathrm{P}-\mathrm{Rh}}(\AA)^{[\mathrm{d}]}$ \\
\hline 1 & - & - & 113.2 & -57.9 & 2.268 \\
\hline 2 & $\mathrm{Na}^{+}$ & 1.9 & 115.8 & -58.7 & 2.252 \\
\hline 3 & $\mathrm{~K}^{+}$ & 2.3 & 122.1 & -58.3 & 2.261 \\
\hline 4 & $\mathrm{Rb}^{+}$ & 2.5 & 121.5 & -58.5 & 2.269 \\
\hline 5 & $\mathrm{Cs}^{+}$ & 2.7 & 121.5 & -58.3 & 2.272 \\
\hline
\end{tabular}

[a] Extracted from ref. [14]. [b] $\beta$ : the angle formed between the $\mathrm{Rh}$ and the two $\mathrm{P}$ atoms. [c] $\theta$ : the mean value of the two $O C_{\mathrm{Ar}}-\mathrm{C}_{\mathrm{Ar}}-\mathrm{C}_{\mathrm{Ar}}-\mathrm{C}_{\mathrm{Ar}} \mathrm{O}$ angles in the two binaphthyl groups. [d] $d_{P-R h}$ : the mean value of the two $\mathrm{P}-\mathrm{Rh}$ bond distances.

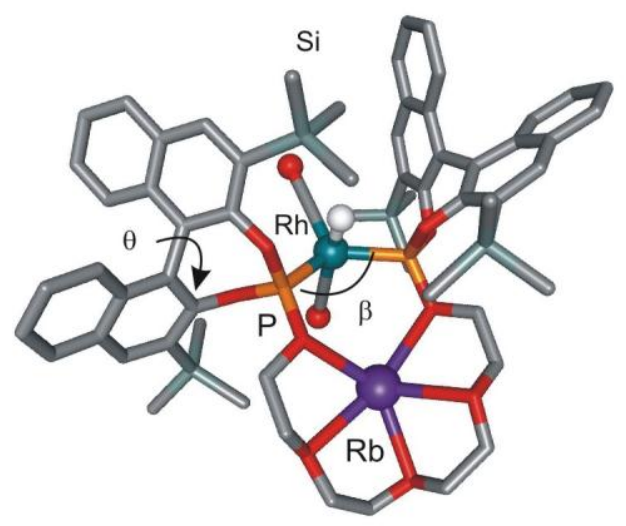

Figure 3. Selected geometrical parameters of the rhodium-derived supramolecular complexes. H-atoms have been omitted for clarity.

$\left(\mathrm{Rb}^{+}\right.$or $\mathrm{Cs}^{+}$); however, the values for the $\mathrm{Na}^{+}$and $\mathrm{K}^{+}$complexes (smaller ionic radii) were smaller (smallest $\Delta \mathrm{d}_{\mathrm{P}-\mathrm{Rh}}=-0.02 \AA$ for $\mathrm{Na}^{+}$). Lastly, the calculated values for the binaphthyl dihedral angle $(\theta)$ of the rhodium complexes of $4 \mathbf{b}$ indicate that the RA forces the binaphthyl units to adopt a conformation with a lower dihedral angle ( $-57.9^{\circ}$ for the complex without RA vs. $-58.4^{\circ}$ (average value) for the complexes containing an alkali metal cation).

Another significant difference between the $\mathrm{Na}^{+}$complex and the rest of complexes with the other cations is the interaction of the alkali ion with the oxygen atoms of the regulation site (RS). The size of $\mathrm{Na}^{+}$is ideal to fit inside the cavity of the RS and consequently the effect on the P-Rh-P bond angle $(\beta)$ is very small (see Table 7 ). In larger cations, the final optimized geometry of the complex is a compromise between increasing the $\mathrm{P}-\mathrm{Rh}-\mathrm{P}$ bond angle (and the $d_{\mathrm{P}-\mathrm{Rh}}$ distance) to enlarge the size of the cavity and moving the cation outside the cavity (see Figure 3 ), thus provoking more larger geometrical changes.

Most interestingly, a plot of the enantiomeric excesses obtained in the AHF of vinyl acetate against the $\mathrm{P}-\mathrm{Rh}-\mathrm{P}$ bond angle $(\beta)$ revealed a maximum in the ee value around the $\beta$ value induced by the rubidium derivative (see Figure 4). On the basis of these findings, we postulated that the significant increase in enantiomeric excess provided by the RAs for vinyl esters $7 a-c$ might be result from adaptation of the $\mathrm{P}-\mathrm{Rh}-\mathrm{P}$ bond angle of the catalyst from a non-ideal value to a value very close to that required for high enantioselectivity. 


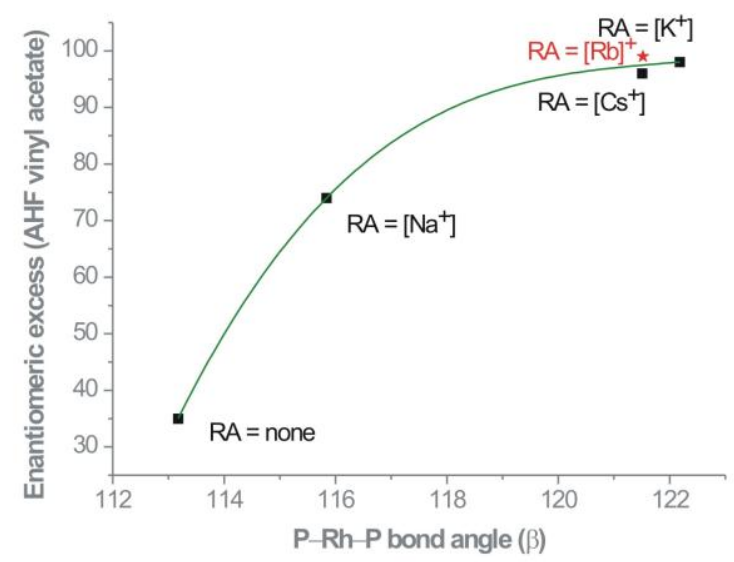

Figure 4. Experimental ee values versus calculated $\mathrm{P}-\mathrm{Rh}-\mathrm{P}$ bond angle values.

\section{Asymmetric hydrogenation of alkenes catalyzed by Rh-complexes of supramolecularly regulated bisphosphites}

Encouraged by the performance of ligands with a distal regulation site in AHF, we shifted our attention to developing supramolecularly regulated catalysts for asymmetric hydrogenation $(\mathrm{AH})$. The rhodium complexes derived from ligands $\mathbf{3 a}$ and $\mathbf{4 a}$ were evaluated as representative pre-catalysts in the $\mathrm{AH}$ of six structurally diverse substrates (10a-f; Scheme 5). Alkali metal (NaBArF, KBArF, RbBArF or CsBArF) or ammonium (6-I, 6-II or 6-III) salts were used as RAs. Ligands 3a and 4a were used throughout the entire study because they provided higher enantioselectivity than those obtained with the 3,3'-disubstituted [1,1'biaryl]-2,2'-diol analogues $\mathbf{3} \mathbf{b}$ and $\mathbf{4} \mathbf{b} .^{[29]}$ The results on $\mathrm{AH}$ are partially summarized in Table 8 , which shows all the results for the catalysts that lack a RA, as well as the highest positive regulation effects (for the full set of results, see Table SI-1 in the Supporting Information).

In almost all the reactions, conversion was complete and enantioselectivity was very high (73 to $99 \%$ ee), with the values being equal to or only slightly lower than the best values reported in the literature for the highest performing ligands in $\mathrm{AHs}{ }^{\left[{ }^{30]}\right.}$ When no RA was used, the ee values ranged from 73 to $98 \%$ (see Table 8 ).$^{[31]}$ Interestingly, ligands 3 a and 4 a gave very similar results, although slightly higher ee values and positive regulation effects associated with the use of an RA were obtained for ligand $\mathbf{3 a}$ than for $\mathbf{4 a}$, as detailed in the discussion that follows.

In the hydrogenations using ligand $3 \mathbf{a}$ and an RA the enantioselectivities varied, but the conversions were all complete. When the standard amount of polyether binder (1.3 equiv of CsBArF relative to the ligand) was used for the $\mathrm{AH}$ of substrate $\mathbf{1 0 b}$, the ee value was slightly (1\%) higher than that observed in the reaction in which no RA was used ( $95 \%$ ee, see footnote e in Table 8 ). With a higher amount of CsBArF (2 equiv of RA relative to the ligand), the ee was $3 \%$ higher than that observed when no RA was used ( $97 \%$ ee, entry 2 , Table 8 ).

Table 8. Catalytic studies on the $\mathrm{AH}$ of alkenes $10 \mathrm{a}-\mathbf{f}$ mediated by bisphosphite ligands $\mathbf{3 a}$ or $\mathbf{4 a}$, with or without $\mathrm{RA}^{[\mathrm{a}]}$

Conv. $(\%),{ }^{[b]}$ ee $(\%)^{[\mathrm{c}]}$ (config. $)^{[\mathrm{d}]}$

\begin{tabular}{|c|c|c|c|c|}
\hline Entry & Ligand & Substrate & $\mathrm{RA}=$ none & Highest performing RA \\
\hline 1 & 3a & $10 a$ & $99,98,(R)$ & 99, 99, $(R)$; with CsBArF \\
\hline 2 & $3 a$ & $10 b$ & $99,94,(S)$ & $99,97,(S)$; with $\mathrm{CsBArF}^{[\mathrm{e}]}$ \\
\hline 3 & $3 a$ & $10 c$ & $99,92,(S)$ & {$[$ [f] } \\
\hline 4 & $3 a$ & $10 d$ & $99,95,(S)$ & [f] \\
\hline 5 & $3 a$ & $10 e$ & $99,93,(S)$ & 99, 94, (S); with NaBArF \\
\hline 6 & $3 a$ & $10 f$ & $59,94,(S)$ & {$[f]$} \\
\hline 7 & $4 a$ & $10 a$ & $99,97,(R)$ & $-[f]$ \\
\hline 8 & $4 a$ & $10 \mathrm{~b}$ & $99,94,(S)$ & 99, 96, (S); with 6-III \\
\hline 9 & $4 a$ & $10 c$ & $99,92,(S)$ & [f] \\
\hline 10 & $4 a$ & $10 d$ & $99,90,(S)$ & 99, 93, (S); with 6-III \\
\hline 11 & $4 a$ & $10 e$ & $99,73,(R)$ & 99, 78, $(R)$; with CsBArF \\
\hline 12 & $4 a$ & $10 f$ & $48,93,(S)$ & $50,95,(S)$; with 6-III \\
\hline
\end{tabular}


[a] The reaction conditions used are those in Scheme 5, unless otherwise stated. The values shown are the average values of at least two independent runs. [b] Conversion, as determined by using ${ }^{1} \mathrm{H}$ NMR spectroscopy. [c] Enantioselectivity, as determined by GC or HPLC using chiral stationary phases. [d] Absolute configuration was assigned by comparison of the specific rotation or the elution order in GC or HPLC (for details, see the Supporting Information). [e] 2.0 equiv of RA relative to 3 a was used. $95 \%$ ee was observed when 1.3 equiv of CsBArF were used. [f] None of the RAs provided any improvement in the ee values relative to the reactions of the ligand alone.

CsBArF had the same effect on the hydrogenation of itaconic acid derivative 10a, as did NaBArF on the hydrogenation of 1 (naphthyl)vinyl acetamide $10 \mathrm{e}$ (up to $1 \%$ higher ee than that observed when no RA was used; Table 8 , 99\% ee in entry 1 and $94 \%$ ee in entry 5 , respectively). However, attempts to enhance the positive regulation effect observed in the reaction of the substrates 10 a and $10 \mathbf{e}$, by increasing the amount of RA (up to 2.0 equiv relative to the ligand $3 \mathbf{a}$ ), were not successful.

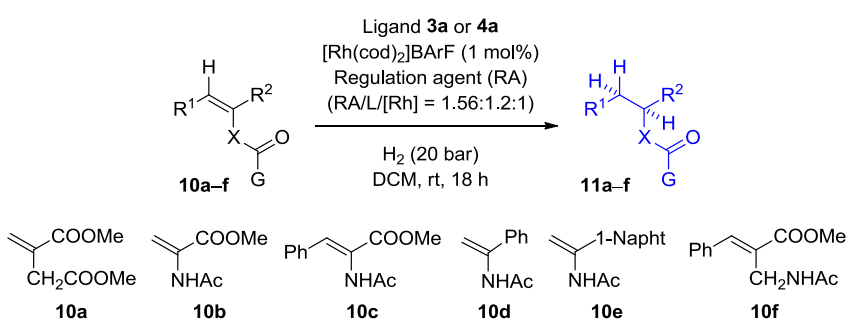

Scheme 5. Asymmetric hydrogenation of alkenes $10 \mathbf{a}-\mathbf{f}$ mediated by ligands $3 \mathbf{a}$ or $\mathbf{4 a}$

For the substrates $\mathbf{1 0 c}, \mathbf{1 0 d}$ and 10f, the rhodium complex of $3 \mathrm{a}$ (without RA) afforded the corresponding products 11c, 11d and 11 with the highest enantioselectivity (from 92 to 95\%; see entries 3, 4 and 6, respectively; Table 8); none of the analogous complexes containing an RA provided any increase in enantioselectivity.

In the AHs using ligand $\mathbf{4 a}$, the rhodium complex of $\mathbf{4 a}$ (without RA) gave the product $\mathbf{1 1} \mathbf{b}$ in $94 \%$ ee, whereas the corresponding ligand containing the $\mathbf{6 - I I I}$ as RA gave a slightly higher value (96\% ee; see entry 8 ; Table 8$)$. For the substrates $10 \mathrm{~d}$-f, the use of ligand 4a and CsBArF or 6-III as RAs gave higher ee values than those obtained in the corresponding reaction in the absence of an RA (see entries 10-12; Table 8): for example, for substrate 10e, the ee increased up to $5 \%$ (78\% ee). Unfortunately, attempts at enhancing the already high levels of enantioselectivity achieved for substrates $10 \mathrm{a}$ and $10 \mathrm{c}$ with ligand $4 \mathrm{a}$ alone, by using a RA, were unsuccessful.

Appropriate combinations of $\left[\mathrm{Rh}(\operatorname{cod})_{2}\right][\mathrm{BArF}]$ and bisphos-phite ligands $\mathbf{3} \mathbf{a}$ or $\mathbf{4 a}$, plus a regulation agent (NaBArF, CsBArF or 6-III), can provide an adaptive catalytic system specific to the substrate geometry: enantioselectivity in these hydrogenations can be maximized by the choice of whether or not to use an RA (and if so, which one to use). These results confirm the validity of our regulation design: easy generation of an efficient catalytic system by combining a ligand and a suitable RA.

\section{Conclusions}

We have reported an efficient synthesis of the new $\alpha, \omega$-bisphosphite ligands $\mathbf{1 - 5 , a - b}$, which incorporate a polyether motif as regulation site. Rhodium complexes of these ligands, either alone or in combination with various regulation agents (RAs), have been assayed in asymmetric hydroformylation (AHF) and asymmetric hydrogenation (AH) of diverse substrates. Strong binding affinities between the ligands and the alkali-metal BArF salts have been demonstrated by using NMR spectroscopy and UV/Vis studies. The binding ability of the studied bisphosphites towards enantiomerically pure ammonium salts was also proven. Complexation studies between these ligands, rhodium precursors (either $\left[\mathrm{Rh}\left(\kappa^{2} \mathrm{O}, \mathrm{O}^{\prime}-\mathrm{acac}\right)(\mathrm{CO})_{2}\right]$ or $\left.\left[\mathrm{Rh}(\mathrm{cod})_{2}\right][\mathrm{BArF}]\right)$, and alkali metal salts $(\mathrm{RbBArF}$ and NaBArF) have demonstrated that 1:1:1 [Rh]/L/RA chelates are formed, which are suitable enantiomerically pure pre-catalysts for AHF and $\mathrm{AH}$.

The presence of substituents at the 3,3' positions of the [1,1'-biaryl]-2,2'-diol-derived phosphite moieties was beneficial to catalytic activity in asymmetric hydroformylation. Furthermore, small amounts of polyether-binder RAs were shown to regulate the activity of the AHF catalysts by biasing the distribution of enantiomers, as evidenced by the fact the rhodium complexes of a ligand and RA enabled up to $82 \%$ higher enantioselectivity compared with those obtained in the reactions of the corresponding complexes withou RA. For example, rhodium complexes of the bisphosphite ligand $\mathbf{4 b}$ that contained a rubidium salt as the regulation agent gave much higher enantioselectivity in the AHF of diversely substituted substrates than those obtained in the AHF of the complexes without RA Computational studies suggest that the increase in enantioselectivity provided by the RAs arise from adaptation of the $\mathrm{P}-\mathrm{Rh}-\mathrm{P}$ bond angle $(\beta)$ to the particular requirements of the substrate.

For asymmetric hydrogenation, the presence of substituents at the 3,3' positions of a [1,1'-biaryl]-2,2'-diol-derived phosphites was detrimental to catalytic activity. Moreover, for substrates

$\mathbf{1 0} \mathbf{a}-\mathbf{f}$, the best enantioselectivities were found when the rhodium complexes of ligands $\mathbf{3 a}$ or $\mathbf{4 a}$ contained an RA (either NaBArF CsBArF or 6-III). The regulation effects in the AH were minor: the rhodium complexes of $\mathbf{3 a}$ or $\mathbf{4 a}$ without RA gave very high enantioselectivities that could not be further enhanced through use of an RA. We are currently designing new supramolecularly regulated catalysts for other pivotal enantioselective transformations. 


\title{
Experimental Section
}

\author{
General procedure for the Rh-mediated asymmetric hydroformylation
}

In a glovebox filled with nitrogen, $\left[\mathrm{Rh}\left(\kappa^{2} \mathrm{O}, \mathrm{O}^{\prime}-\mathrm{acac}\right)(\mathrm{CO})_{2}\right]$ ( $\mathrm{ca} .2 .3 \mu \mathrm{mol}$ in $65 \mu \mathrm{L}$ of toluene) was added to a stirred solution of ligand 1-5 (ca. $2.7 \mu \mathrm{mol}$ in $360 \mu \mathrm{L}$ of toluene) and the BArF salt (ca. $3.6 \mu \mathrm{mol}$ in $27 \mu \mathrm{L}$ of THF) in a $2 \mathrm{~mL}$ vial. The substrate (ca. $230 \mu \mathrm{mol})$, dodecane (ca. $69 \mu \mathrm{mol})$, and additional toluene were charged to provide the desired final solution of toluene/THF (97:3 v/v). The vial was then taken out of the glovebox and transferred into an autoclave. The autoclave was purged three times with syngas $\left(1: 1 \mathrm{H}_{2} / \mathrm{CO}\right.$ at a pressure not higher than 10 bar) and finally, the autoclave was pressurized with syngas to the desired pressure. The reaction mixture was stirred at $40^{\circ} \mathrm{C}$ for the required reaction time. The reaction was cooled and the pressure was carefully released in a well-ventilated hood. Conversion and branched-to-linear product ratio for the hydroformylation products of $7 \mathbf{a}-\mathbf{d}$ were determined by using GC analysis. Conversion and branch-to-linear ratio for the hydroformylation products of $7 \mathrm{e}$ were determined by using ${ }^{1} \mathrm{H}$ NMR analysis. The enantiomeric excesses for the hydroformylation products of 7a-e were determined by GC using chiral stationary phases (for details, see the Supporting Information). For a hydroformylation reaction with higher amounts of substrate and a higher $\mathrm{S} / \mathrm{C}$ ratio, see the Supporting Information.

\section{General procedure for the Rh-mediated asymmetric hydrogenation}

In a glovebox filled with nitrogen, $\left[\mathrm{Rh}(\operatorname{cod})_{2}\right] \mathrm{BArF}(0.01$ equiv in dichloromethane) was added to a $2 \mathrm{~mL}$ vial equipped with a magnetic bar and the substrate (ca. $15 \mathrm{mg}, 1$ equiv). A previously stirred solution $(10 \mathrm{~min}$ ) of the ligand ( 0.012 equiv) and regulation agent ( 0.0156 equiv) were then added to this solution. Additional dichloromethane was charged to provide the desired final concentration of substrate $(0.2 \mathrm{M})$. The vial was then taken out of the glovebox and transferred into an autoclave. The autoclave was purged three times with $\mathrm{H}_{2}$ at a pressure not higher than 20 bar and, finally, the autoclave was pressurized with $\mathrm{H}_{2}$ to the desired pressure. The reaction mixture was stirred at room temperature for $18 \mathrm{~h}$. The pressure was carefully released in a well-ventilated hood. The conversion was determined by ${ }^{1} \mathrm{H}$ NMR spectroscopy and enantiomeric excesses were determined by GC or HPLC analysis using chiral stationary phases (for details, see the Supporting Information).

\section{Acknowledgements}

The authors thank MINECO (CTQ2014-60256-P, CTQ2014-57393-C2-1-P and Severo Ochoa Excellence Accreditation 2014-2018 SEV-2013-0319) and the ICIQ Foundation for financial support. Financial support from CELLEX Foundation through the CELLEXICIQ high throughput experimentation platform is gratefully acknowledged. L. R. thanks the ICIQ Foundation for a stipend. Dr. H. Fernández-Pérez is acknowledged for his help in the preparation of the manuscript.

Keywords: asymmetric catalysis $\bullet$ enantioselectivity $\bullet$ hydroformylation $\bullet$ hydrogenation $\bullet$ rhodium $\bullet$ supramolecular chemistry

[1] For general references on this topic, see for example: a) Comprehensive Asymmetric Catalysis, Vols. I-III, 1st ed. (Eds.: E. N. Jacobsen, A. Pfaltz, H. Yamamoto), Springer, Heidelberg, 1999; (b) Comprehensive Chirality, Vols. 1-9, (Eds.: E. M. Carreira, H. Yamamoto), Elsevier Science, Oxford, 2012.

[2] See, for example: a) B. M. Trost, D. L. Van Vranken, C. Bingel, J. Am. Chem. Soc. 1992, 114, 9327-9343; b) T. V. Rajanbabu, A. L. Casalnuovo, T. A. Ayers, Adv. Catal. Processes 1997, 2, 1-41; c) D. Popa, C. Puigjaner, M. Gómez, J. Benet-Buchholz, A. Vidal-Ferran, M. A. Pericàs, Adv. Synth. Catal. 2007, 349, 2265-2278.

[3] a) H. Fernández-Pérez, M. A. Pericàs, A. Vidal-Ferran, Adv. Synth. Catal. 2008, 350, 1984-1990; b) H. Fernández-Pérez, S. M. A. Donald, I. J. Munslow, J. Benet-Buchholz, F. Maseras, A. Vidal-Ferran, Chem. Eur. J. 2010, 16, 6495-6508.

[4] See, for example: D. Leung, S. O. Kang, E. V. Anslyn, Chem. Soc. Rev. 2012, 41, 448-479.

[5] For a summary on the use of supramolecular interactions in the construction of (enantioselective) catalysts, see: a) M. Raynal, P. Ballester, A. Vidal-Ferran, P. W. N. M. van Leeuwen, Chem. Soc. Rev. 2014, 43, 1660-1733; b) M. Raynal, P. Ballester, A. Vidal-Ferran, P. W. N. M. van Leeuwen, Chem. Soc. Rev. 2014, 43, 1734-1787.

[6] See, for example: a) A. M. Costa, C. Jimeno, J. Gavenonis, P. J. Carroll, P. J. Walsh, J. Am. Chem. Soc. 2002, 124, 6929-6941; b) R. Eelkema, B. L. Feringa, J. Am. Chem. Soc. 2005, 127, 13480-13481; c) J. Etxebarria, H. Degenbeck, A. S. Felten, S. Serres, N. Nieto, A. Vidal-Ferran, J. Org. Chem. 2009, 74, 8794-8797; d) P. Dydio, C. Rubay, T. Gadzikwa, M. Lutz, J. N. H. Reek, J. Am. Chem. Soc. 2011, 133, 17176-17179; e) H. Degenbeck, A. S. Felten, J. Etxebarria, E. C. Escudero-Adan, J. Benet-Buchholz, A. Vidal-Ferran, Cryst. Growth Des. 2012, 12, 2719-2723; f) H. Degenbeck, A. S. Felten, E. C. Escudero-Adan, J. Benet-Buchholz, L. Di Bari, G. Pescitelli, A. Vidal-Ferran, Inorg. Chem. 2012, 51, 8643-8645.

[7] For example, see: a) N. C. Gianneschi, P. A. Bertin, S. T. Nguyen, C. A. Mirkin, L. N. Zakharov, A. L. Rheingold, J. Am. Chem. Soc. 2003, 125, 1050810509; b) N. C. Gianneschi, S.-H. Cho, S. B. T. Nguyen, C. A. Mirkin, Angew. Chem. Int. Ed. 2004, 43, 5503-5507; Angew. Chem. 2004, 116, 5619-5623; c) D. Sud, T. B. Norsten, N. R. Branda, Angew. Chem. Int. Ed. 2005, 44, 2019-2021; Angew. Chem. 2005, 117, 2055-2057; d) J. Wang, B. L. Feringa, Science 2011, 331, 1429-1432.

[8] For example, see: a) R. Bellini, S. H. Chikkali, G. Berthon-Gelloz, J. N. H. Reek, Angew. Chem., Int. Ed. 2011, 50, 7342-7345; Angew. Chem. 2011, 123, 7480-7483; b) R. Bellini, J. N. H. Reek, Chem. Eur. J. 2012, 18, 7091-7099; c) R. Bellini, J. N. H. Reek, Chem. Eur. J. 2012, 18, $13510-13519$.

[9] For example, see: a) M. L. Clarke, J. A. Fuentes, Angew. Chem. Int. Ed. 2007, 46, 930-933; Angew. Chem. 2007, 119, 948-951; b) Y. Li, B. Ma, Y. He, F. Zhang, Q.-H. Fan, Chem. Asian J. 2010, 5, 2454-2458; c) P. W. N. M. van Leeuwen, D. Rivillo, M. Raynal, Z. Freixa, J. Am. Chem. Soc. 2011, 133, 1856218565; d) F.-T. Song, G.-H. Ouyang, Y. Li, Y.-M. He, Q.-H. Fan, Eur. J. Org. Chem. 2014, 2014, 6713-6719.

[10] I. Mon, D. A. Jose, A. Vidal-Ferran, Chem. Eur. J. 2013, 19, 2720-2725.

[11] For examples of binding studies on crown ethers, see: J. W. Steed, Coord. Chem. Rev. 2001, 215, $171-221$.

[12] D. A. Jose, I. Mon, H. Fernandez-Perez, E. C. Escudero-Adan, J. Benet-Buchholz, A. Vidal-Ferran, Org. Lett. 2011, 13, 3632-3635.

[13] a) P. W. N. M. van Leeuwen, P. C. J. Kamer, C. Claver, O. Pamies, M. Dieguez, Chem. Rev. 2011, 111, 2077-2118; b) M. M. Pereira, M. J. F. Calvete, R. M. B. Carrilho, A. R. Abreu, Chem. Soc. Rev. 2013, 42, 6990-7027.

[14] F. A. Cotton, G. Wilkinson, Advanced Inorganic Chemistry: A Comprehensive Text., 3rd ed., Wiley, New York, 1972.

[15] See the Supporting Information for details. 
[16] NMR titration data were analysed using HypNMR software (ver. 2008: Protonic Software): a) C. Frassineti, S. Ghelli, P. Gans, A. Sabatini, M. S. Moruzzi, A. Vacca, Anal. Biochem. 1995, 231, 374-382; b) C. Frassineti, L. Alderighi, P. Gans, A. Sabatini, A. Vacca, S. Ghelli, Anal. Bioanal. Chem. 2003, 376, 10411052. UV/Visible titration data were analysed by using multivariate factor analysis. SPECFIT software (ver. 3.0; Spectra Software Associates) was used: c) H. Gampp, M. Maeder, C. J. Meyer, A. D. Zuberbuehler, Talanta 1985, 32, 95-101; d) H. Gampp, M. Maeder, C. J. Meyer, A. D. Zuberbuehler, Talanta 1986, 33, 943-951.

[17] See, for example: J. S. Renny, L. L. Tomasevich, E. H. Tallmadge, D. B. Collum, Angew. Chem., Int. Ed. 2013, 52, 11998-12013; Angew. Chem. 2013, 125, 12218-12234.

[18] F. P. Schmidtchen, in Analytical Methods in Supramolecular Chemistry (Ed.: C. A. Schalley), Wiley-VCH, Weinheim, 2007, p. 55.

[19] a) L. Damoense, M. Datt, M. Green, C. Steenkamp, Coord. Chem. Rev. 2004, 248, 2393-2407; b) S. H. Chikkali, R. Bellini, B. de Bruin, J. I. van der Vlugt, J. N. H. Reek, J. Am. Chem. Soc. 2012, 134, 6607-6616.

[20] R. Franke, D. Selent, A. Boerner, Chem. Rev. 2012, 112, 5675-5732.

[21] Addition of increasing amounts of alkali metal BArF salts to a solution of $\mathbf{5 b}$ did not induce any change in its spectra, which led us to conclude that weak binding was occurring.

[22] The required catalyst amount was obtained from a substrate/RbBArF/ligand $4 \mathbf{b} /[\mathrm{Rh}]$ ratio $=100: 0.156: 0.12: 0.1$ in a solution with a vinyl acetate concentration of $1 \mathrm{M}$. Under these conditions, the ligand and RbBArF concentrations in the reaction mixture were $1.2 \times 10^{-3} \mathrm{M}$ and $1.56 \times 10^{-3} \mathrm{M}$, respectively. The association constant between $\mathbf{4 b}$ and RbBArF in toluene/THF $(97: 3, \mathrm{v} / \mathrm{v})$ was $1 \times 10^{4} \mathrm{M}^{-1}$, which translates into the formation of the $\mathrm{RbBArF} \cdot \mathbf{4 b}$ complex to an extent of about $84 \%$. Addition of a six-fold excess of RbBArF relative to $\mathbf{4 b}$ at the working concentration ensured the formation of the RbBArF•4b complex to an extent of $>98 \%$. However, hydroformylation of $7 \mathbf{a}$ using a substrate/RbBArF/ligand $4 \mathbf{b} /[\mathrm{Rh}] \mathrm{ratio}=100: 0.72: 0.12: 0.1 \mathrm{did}$ not offer any advantages relative to the previously mentioned conditions.

[23] G. W. Wong, C. R. Landis, Angew. Chem., Int. Ed. 2013, 52, 1564-1567; Angew. Chem. 2013, 125, 1604-1607.

[24] C. J. Cobley, R. D. J. Froese, J. Klosin, C. Qin, G. T. Whiteker, K. A. Abboud, Organometallics 2007, 26, 2986-2999.

[25] In the absence of RA, the b/l ratio and enantioselectivity were identical with or without incubation time $(\mathrm{b} / \mathrm{l}$ ratio $=94: 6 ; e e=37 \%)$.

[26] X. Zhang, B. Cao, Y. Yan, S. Yu, B. Ji, X. Zhang, Chem. Eur. J. 2010, 16, 871-877.

[27] The geometry of all the complexes included in this study was optimised at the BP86-D3/def2-TZVPD level of theory within the program TURBOMOLE ver. 6.4 (R. Ahlrichs, M. Baer, M. Haeser, H. Horn, C. Koelmel, Chem. Phys. Lett. 1989, 162, 165-169). The def2-TZVPD basis set was used for all atoms. It employs effective core potentials for Rh (ECP-28, as in D. Andrae, U. Haeussermann, M. Dolg, H. Stoll, H. Preuss, Theor. Chim. Acta 1990, 77, 123-141). For the calculations, the BP86 functional with Grimme's latest available correction for dispersion (D3, as reported by S. Grimme, J. Antony, S. Ehrlich, H. Krieg, J. Chem. Phys. 2010, 132, 154104/1-154104/19), was used.

[28] See the following reference and those cited therein: S. H. Chikkali, J. I. van der Vlugt, J. N. H. Reek, Coord. Chem. Rev. 2014, $262,1-15$.

[29] The presence of substituents at the 3,3' positions of a [1,1'-biaryl]-2,2'-diol-derived phosphites is detrimental to catalytic activity in AH: See, for example: a) A. Korostylev, A. Monsees, C. Fischer, A. Borner, Tetrahedron: Asymmetry 2004, 15, 1001-1005; b) L. Pignataro, S. Carboni, M. Civera, R. Colombo, U. Piarulli, C. Gennari, Angew. Chem. Int. Ed. 2010, 49, 6633-6637; Angew. Chem. 2010, 122, 6783-6787. The AH of 10b using ligands 3a or 4a gave the hydrogenated product in complete conversion and $94 \%$ ee (entries 2 and 8 , Table 8 ), whereas the ligands $\mathbf{3 b}$ or $\mathbf{4 b}$ mediated the $\mathrm{AH}$ in complete conversion, but with only 86 and $74 \%$ ee, respectively (for clarity, these results have not been included in Table 8 ).

[30] For milestone ligands whose Rh-complexes mediate the hydrogenation of 10a-d in $99 \%$ ee see, for example: a) H. Fernández-Pérez, P. Etayo, A. Panossian, A. Vidal-Ferran, Chem. Rev. 2011, 111, 2119-2176; b) J.-H. Xie, S.-F. Zhu, Q.-L. Zhou, Chem. Rev. 2011, 111, 1713-1760. For the highest performing ligands in the Rh-mediated hydrogenation of 10e and 10f, see: c) T. Imamoto, K. Tamura, Z. Zhang, Y. Horiuchi, M. Sugiya, K. Yoshida, A Yanagisawa, I. D. Gridnev, J. Am. Chem. Soc. 2012, 134, 1754-1769; d) L. Pignataro, M. Boghi, M. Civera, S. Carboni, U. Piarulli, C. Gennari, Chem. Eur. J. 2012, 18, 1383-1400.

[31] These results corroborate a recent report that rhodium complexes of phosphorus ligands with long chains between the two phosphorus binding groups mediate AHs with high enantioselectivity. See, for example: a) K. N. Gavrilov, O. G. Bondarev, A. I. Polosukhin, Russ. Chem. Rev. 2004, 73, 671-699; b) G. Farkas, S. Balogh, J. Madarasz, A. Szoellosy, F. Darvas, L. Uerge, M. Gouygou, J. Bakos, Dalton Trans. 2012, 41, 9493-9502. 